\title{
Calciphylaxis: a complication of end-stage renal disease improved by parathyroidectomy
}

\author{
John C. Maroulis, ${ }^{1}$ Constantinos Fourtounas, ${ }^{2}$ John G. Vlachojannis, ${ }^{2}$ \\ Nikolaos Siasos, ${ }^{1}$ Dionysios Karavias, ${ }^{1}$ Dionysios Chartoumpekis, ${ }^{3}$ \\ Ioannis Habeos ${ }^{3}$
}

${ }^{1}$ Department of Surgery, ${ }^{2}$ Department of Internal Medicine-Nephrology, ${ }^{3}$ Department of Internal MedicineEndocrinology, Patras University School of Medicine

\begin{abstract}
A 43-year old Caucasian male with end-stage renal disease presented with painful skin lesions and high calcium phosphate product that did not respond to medical treatment. Skin biopsy confirmed the diagnosis of calciphylaxis. Urgent parathyroidectomy was performed and resulted in decrease in the calcium phosphate product and improvement of his symptoms and signs.
\end{abstract}

Key words: Calciphylaxis, Chronic renal failure, Parathyroidectomy

\section{INTRODUCTION}

The phenomenon of calciphylaxis is rare but potentially fatal. It is characterized by systemic medial calcification of the arteries and tissue ischemia., ${ }^{1,2}$ t usually, though not exclusively, occurs in patients with end-stage renal disease who are on dialysis ${ }^{3}$ or who have recently received a renal transplant, ${ }^{4}$ and is typically characterized by areas of ischemic necrosis that usually develops in the dermis, subcutaneous fat and, less often, in muscle. ${ }^{5}$ The pathogenesis of calciphylaxis is poorly understood. Hyperparathyroidism, vitamin D supplementation, hyper-

Address correspondence and requests for reprints to: Ioannis Habeos, Department of Internal Medicine-

Endocrinology, Patras University School of Medicine,

Tel.: +30 2610 999690; Fax: +30 2610 999696,

e-mail: ihabeos@med.upatras.gr

Received 07-05-06, Revised 25-06-06, Accepted 01-07-06 phosphatemia and plasma calcium level have been incriminated as possible pathogenetic factors. The role of urgent parathyroidectomy is uncertain because the various series thus far reported suffer from selection bias and include small numbers of patients.

We describe calciphylaxis in a patient with endstage renal disease on Continuous Ambulatory Peritoneal Dialysis (CAPD) on whom urgent parathyroidectomy was carried out because of lack of response to medical treatment.

\section{CASE REPORT}

A 43-year old Caucasian male with end-stage renal disease presented to the emergency room with fever, weight loss, weakness and painful skin lesions.

The patient was diagnosed with end-stage renal disease attributed to glomerulonephritis and had 
started maintenance hemodialysis 10 years earlier. Six years later he had been switched to Continuous Ambulatory Peritoneal Dialysis (CAPD).

Secondary hyperparathyroidism had been present for years and was being treated with 1-alpha hydroxy vitamin D3 and calcium carbonate. He had also received for the past 2 years intravenous 1-alpha hydroxy vitamin D3 and calcium carbonate therapy during dialysis in an attempt to control hyperparathyroidism. In addition, he had been administered erythropoietin subcutaneously.

Three weeks before the present admission, he developed a pelvic abscess that had been treated with surgical drainage and antibiotics (ciprofloxacin and clindamycin).

One week before admission the patient developed an extremely painful linear violaceous discoloration, resembling livedo reticularis, on the extensor surface of his right thigh, which progressively increased in size. Subsequently, similar painful lesions appeared on his left thigh and tibia, prepuce and on the glans penis. All lesions progressed into firm, non-ulcerating necrotic plaques (Figure 1).

Clinical examination revealed a thin, cachectic man with pallor of his mucous membranes, in obvious distress as a result of pain. The blood pressure was $170 / 100 \mathrm{mmHg}$, the pulse rate was $100 / \mathrm{min}$, respirations were $20 / \mathrm{min}$ and body temperature was $38^{\circ} \mathrm{C}$. Examination of the cardiovascular and respi-

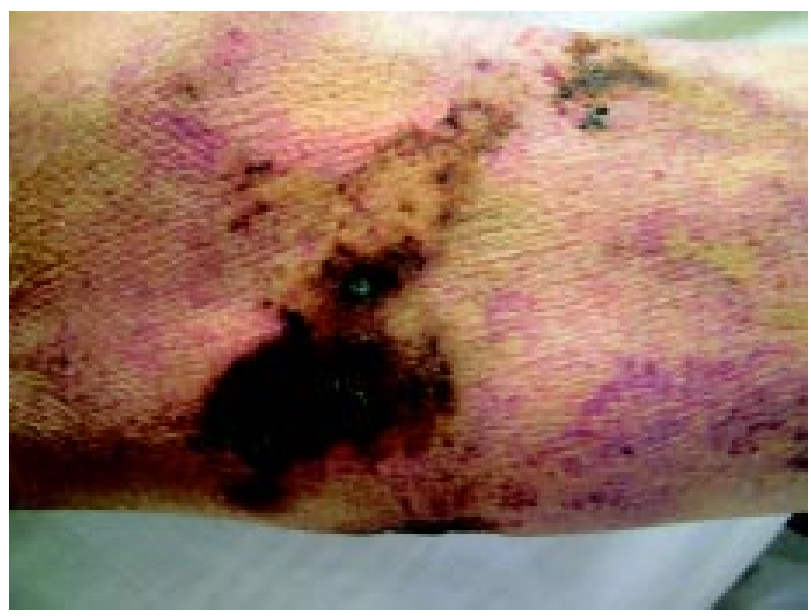

Figure 1. Left thigh skin lesions before parathyroidectomy. ratory systems disclosed a grade 2 systolic murmur at the left sternal border. Examination of his lower extremities revealed tender, palpable subcutaneous nodules over his thighs and legs. There was no evidence of cutaneous vasculitis, abnormal bruising or generalized rash. Firm, painless masses were palpated in the left supraclavicular fossa as well as in the right groin. Extensive, well-demarcated necrotic plaques with irregular borders and perilesional violaceous discoloration on the lower extremities and in the genital region were noted. Additionally, in the surrounding skin multiple brown and firm subcutaneous nodules ( $1 \mathrm{~cm}$ diameter $)$ in linear configuration were present. The patient mentioned a $10 \mathrm{~kg}$ weight loss over the preceding month. The laboratory findings were as follows (Table 1): corrected-calcium was $2.57 \mathrm{mmol} / \mathrm{L}$, phosphate 2.784 $\mathrm{mmol} / \mathrm{L}$, albumin $2.9 \mathrm{gm} / \mathrm{dl}$, and PTH $1472.5 \mathrm{pmol} /$

Table 1. Laboratory parameters on admission and after parathyroidectomy

\begin{tabular}{|c|c|c|}
\hline Parameter & On admission & $\begin{array}{c}\text { Day of } \\
\text { discharge }\end{array}$ \\
\hline Hemoglobin $(\mathrm{g} / \mathrm{dl})$ & 10 & 9.8 \\
\hline White cell count (per $\mathrm{mm}^{3}$ ) & 14220 & 12000 \\
\hline Platelet count (per mm³) & 580000 & 470000 \\
\hline Prothrombin time (sec) & 12.3 & 12.0 \\
\hline Partial thromboplastin time(sec) & 38 & 36 \\
\hline Urea $(\mathrm{mg} / \mathrm{dl})$ & 178 & 105 \\
\hline Creatinine $(\mathrm{mg} / \mathrm{dl})$ & 7.7 & 5.3 \\
\hline Albumin (g/dl) & 2.9 & 2.3 \\
\hline Calcium (mmol/L) (2.23-2.63) & 2.35 & 1.875 \\
\hline Corrected-calcium (mmol/L) & 2.57 & 2.2 \\
\hline $\begin{array}{l}\text { Calcium-phosphate product } \\
(\mathrm{mmol} / \mathrm{L})^{2}(4.2-5.6)\end{array}$ & 7.15 & 3.66 \\
\hline Phosphate (mmol/L) (0.81-1.45) & 2.784 & 1.664 \\
\hline PTH (pmol/L) (1-6.8) (IRMA) & 1472.5 & 92.2 \\
\hline Magnesium $(\mathrm{mmol} / \mathrm{L})(0.65-1.05)$ & 0.96 & 0.92 \\
\hline Glucose $(\mathrm{mmol} / \mathrm{L})(3.6-6.4)$ & 5.23 & 5.78 \\
\hline Sodium (mmol/L) & 133 & 135 \\
\hline Potassium $(\mathrm{mmol} / \mathrm{L})$ & 5 & 4.5 \\
\hline Aspartate aminotransferase (U/L) & 18 & 20 \\
\hline Alanine aminotransferase (U/L) & 23 & 28 \\
\hline Alkaline phosphatase (U/L) & 594 & 500 \\
\hline Creatine kinase (U/L) & 107 & 98 \\
\hline
\end{tabular}


L. An electrocardiogram (ECG) showed sinus rhythm with signs of left ventricular hypertrophy (PR $0.16 \mathrm{sec}$, QRS $0.08 \mathrm{sec}$, ST flattened in aVL and I).

Plain X-rays of his extremities showed vascular calcifications.

The scanning of his parathyroids with Tc99mSestamibi showed three areas of increased uptake. The aforementioned areas corresponded to the following anatomic locations: a) right lower thyroid lobe, b) middle area of the right thyroid lobe, and c) the middle area of the left lobe. The findings were consistent with parathyroid hyperplasia due to secondary hyperparathyroidism.

The bone scan revealed findings compatible with renal osteodystrophy. In particular, there was in-

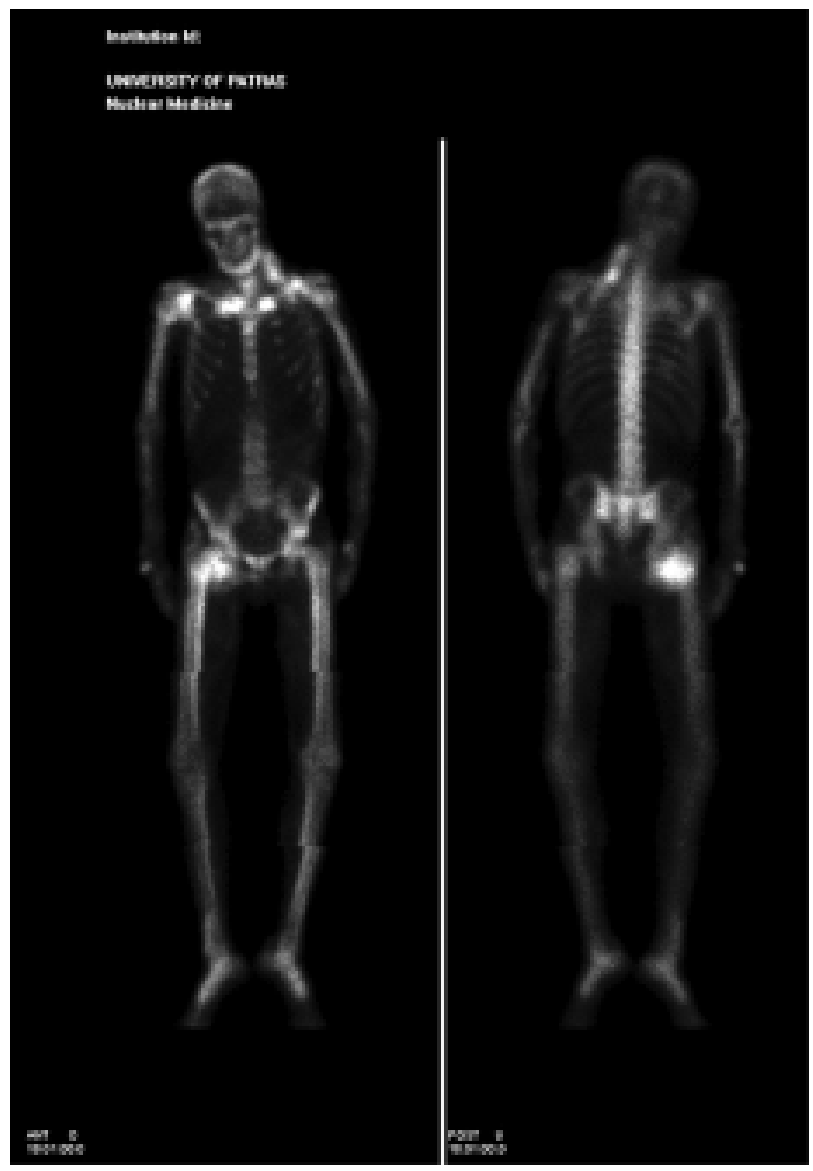

Figure 2. Bone scan. Increased uptake in both clavicles, extraskeletal uptake by the skin lesions and tumoral calcinosis at the left supraclavicular fossa and the R. groin. creased uptake at the medial third of both clavicles (brown tumors), extra skeletal uptake at the described skin lesions (calciphylaxis) and tumoral calcinosis at the left supraclavicular fossa and the right groin (Figure 2).

Histopathological examination of biopsy specimens derived from the skin lesions revealed necrosis of the epidermis and of the papillary dermis and a generalized involvement of small vessels characterized by medial calcification, intimal proliferation, microthrombi formation and infiltration of numerous neutrophils and some macrophages.

A computed tomography (CT) scan of the chest and the abdomen after the administration of contrast material showed brown tumors of the sternal ends, of both clavicles as well as the medial aspect of the left scapula and calcifications of the aorta, iliac and coronary arteries.

Aggressive wound care as well as a pain control program were initiated. Because of the high calcium-phosphate product, an effort was made to correct the abnormality by ceasing vitamin D supplementation, substituting sevelamer hydrochloride (Renagel) for calcium carbonate as phosphate binders and using low calcium dialysate, however, without success. Given the high mortality associated with calciphylaxis and the deterioration of his clinical status as a consequence of wound superinfection, an urgent parathyroidectomy was decided upon. During surgery all of his parathyroid glands were identified and found to be hyperplastic. Three and a half of them were removed. After surgery PTH dropped promptly to $92.2 \mathrm{pmol} / \mathrm{L}$ and his calcium-phosphate product dropped to 3.6. Over the next few days his skin lesions improved and the patient was discharged two weeks later with corrected-calcium $2.2 \mathrm{mmol} /$ $\mathrm{L}$, phosphate $1.664 \mathrm{mmol} / \mathrm{L}$, albumin $2.3 \mathrm{mg} / \mathrm{dl}, \mathrm{Mg}$ $0,92 \mathrm{mmol} / \mathrm{L}$ and calcium-phosphate product 3.6.

\section{DISCUSSION}

The diagnosis of calciphylaxis requires a high index of suspicion in a uremic patient who presents with characteristic lesions against a background of abnormal biochemistry. Our patient had chronic renal failure on peritoneal dialysis with development 
of severe secondary hyperparathyroidism $(\mathrm{PTH}=$ $1472.5 \mathrm{pmol} / \mathrm{l}$ ) and high calcium phosphate product (93) because of poor compliance with his phosphate binders. However, these factors are commonly present in end-stage renal disease and none is sufficient to explain the calciphylaxis occurrence. The specific factors precipitating this disorder in an individual patient are not known. In our case, a pelvic abscess preceded the development of calciphylaxis, which might have acted as a trigger. It is generally acceptable to perform urgent parathyroidectomy to treat this disorder after medical therapy has failed. The surgical series are small and no definite conclusions can be drawn. ${ }^{6,7}$ Our patient did not respond to medical treatment. After parathyroidectomy, we noticed a significant drop in calcium-phosphate product and amelioration of the skin lesions as well as of the overall status of the patient.

In conclusion, an end-stage renal failure patient presented with calciphylaxis and, after failure of medical treatment, he was treated successfully with parathyroidectomy.

\section{REFERENCES}

1. Adrogue HJ, Frazier MR, Zeluff B, Suki WN, 1981 Systemic calciphylaxis revisited. Am J Nephrol 1: 177183.

2. Kent RB, Lylerly RT, 1994 Systemic calciphylaxis. South Med J 87: 278-281.

3. Budisavljevic MN, Cheek D, Ploth DW, 1996 Calciphylaxis in chronic renal failure. J Am Soc Nephrol 7: 978-982.

4. Perloff LJ, Spence RK, Grossman RA, Barker CF, 1979 Lethal posttransplantation calcinosis. Transplantation 27: 21-25.

5. Janigan DT, Hirsch DJ, Klassen GA, MacDonald AS, 2000 Calcified subcutaneous arterioles with infarcts of the subcutis and skin («calciphylaxis») in chronic renal failure. Am J Kidney Dis 35: 588-597.

6. Fine A, Zacharias J, 2002 Calciphylaxis is usually nonulcerating: Risk factors, outcome and therapy. Kidney Int 61: 2210-2217.

7. Kang AS, McCarthy JT, Rowland C, et al, 2000 Is calciphylaxis best treated surgically or medically? Surgery 128: 967-972. 